\title{
ENCONTRABILIDADE DA INFORMAÇÃO NO AMBIENTE TECHNOLOGY, ENTERTAINMENT AND DESIGN
}

\author{
ENCONTRABILIDAD DE LA INFORMACIÓN EN EL \\ AMBIENTE TECHNOLOGY, ENTERTAINMENT AND \\ DESIGN
}

\author{
Nathália Britto Pinheiro da Silva* \\ Fernando Luiz Vechiato ** \\ Silvana Aparecida Borsetti Gregorio Vidotti ***
}

\begin{abstract}
RESUMO:
Introdução: A disseminação e o compartilhamento da informação e conhecimento são o principal objetivo dos ambientes informacionais digitais, como a organização Technology, Entertainment and Design (TED), que tem o propósito de divulgar as palestras que são gravadas, as quais abordam diversos assuntos em formato de vídeo digital. Considerando a relevância desse ambiente, torna-se importante refletir a respeito da Encontrabilidade da Informação disponível, com a intenção de compreender se a sua Arquitetura da Informação contempla atributos que facilitam a localização, o acesso, o uso e a apropriação da informação pelos usuários. Objetivo: Assim, os objetivos desta pesquisa foram avaliar a Encontrabilidade da Informação no ambiente informacional digital TED a partir dos seus atributos e analisar os resultados à luz das dimensões da Arquitetura da Informação, os quais são o conteúdo, o contexto e o usuário. Metodologia: Trata-se de uma pesquisa documental e exploratória, com abordagem qualitativa e com a utilização de observação participante. Resultados: Os resultados revelam que os atributos de Encontrabilidade da Informação presentes no TED indicam consonância com a missão organizacional e proporcionam a interação do sujeito informacional com a interface. Conclusões: A

*Mestranda em Ciência da Informação pelo Programa de Pós-Graduação em Ciência da Informação da UNESP. Bolsista CNPq. E-mail: nathaliabritto6@gmail.com.

**Doutorando em Ciência da Informação pelo Programa de Pós-Graduação em Ciência da Informação da UNESP. Docente do Departamento de Ciência da Informação da Universidade Federal do Rio Grande do Norte (UFRN). E-mail: vechiato2004@yahoo.com.br.

*** Doutora em Educação. Professora do Programa de Pós-Graduação em Ciência da Informação da UNESP. E-mail: vidotti@marilia.unesp.br
\end{abstract}


ausência de alguns atributos pode comprometer a apropriação da informação pelos sujeitos informacionais.

Palavras-chave: Encontrabilidade da Informação. Arquitetura da Informação. Ambiente informacional digital. Disseminação da informação.

\section{INTRODUÇÃO}

Com a evolução das Tecnologias da Informação e Comunicação (TIC) e da Word Wide Web (WWW), emergem os ambientes informacionais digitais, que disseminam recursos informacionais em diferentes formatos, como texto, imagem, áudio e vídeo.

O formato vídeo, em especial, permite a disseminação e o compartilhamento da informação de forma dinâmica, atendendo ao constante crescimento dos dispositivos móveis e redes sociais.

Para acompanhar essa tendência, o Technology, Entertainment and Design (TED), como uma organização sem fins lucrativos, criou um ambiente na web para atender a sua missão organizacional de divulgar ideias inovadoras, relacionadas com questões como: científicas, econômicas, sociais, culturais e políticas.

O ambiente informacional digital TED tornou-se um dos meios de comunicação e divulgação de suas palestras por meio dos vídeos digitais que podem ser baixados (downloads) gratuitamente.

Entende-se que os vídeos são conteúdos informacionais que necessitam ser representados, organizados e disseminados de acordo com as necessidades dos sujeitos, favorecendo sua encontrabilidade. Dessa forma, torna-se importante refletir a respeito da Encontrabilidade da Informação disponível no ambiente TED, com vistas a compreender se sua Arquitetura da Informação projetada contempla atributos que facilitam a localização, o acesso, o uso e a apropriação da informação pelos seus usuários.

Assim, o problema da pesquisa concentra-se em duas questões: Quais atributos da Encontrabilidade da informação estão presentes no ambiente

Inf. Inf., Londrina, v. 22, n. 2, p. 481 - 496, maio/ago., 2017. http:www.uel.br/revistas/informacao/ 
TED.com? Como esses atributos no ambiente impactam na missão organizacional?

Para responder ao problema, objetivamos avaliar a Encontrabilidade da Informação no ambiente informacional digital TED a partir dos Atributos de Encontrabilidade da Informação (AEI) desenvolvidos por Vechiato e Vidotti (2014) e analisar os resultados à luz das dimensões da Arquitetura da Informação (Al) propostos por Rosenfeld, Morville e Arango (2015), quais sejam: contexto, conteúdo e usuários.

Para isso, por meio de pesquisa documental e exploratória, foi realizada uma revisão de literatura sobre Encontrabilidade da Informação, explorando o percurso do conceito na Ciência da Informação e os atributos de acordo com os pressupostos teóricos estabelecidos para a análise do ambiente. A análise propriamente dita foi realizada a partir de pesquisa descritiva, com abordagem qualitativa, utilizando como técnica a observação do participante, conferindo quais atributos estão contemplados no ambiente, por meio do Quadro 2 Análise dos atributos no ambiente TED com opções de SIM (S) e NÃO (N) e observações descritivas sobre a presença ou ausência de cada atributo.

A pesquisa justifica-se pelo fato do TED ter como missão a divulgação de ideias que contemplam informação e conhecimento. Dessa forma, as informações disponíveis devem estar estruturadas de forma adequada, favorecendo sua encontrabilidade.

\section{ENCONTRABILIDADE DA INFORMAÇÃO}

Com a expansão da Internet, o acesso das informações digitais no ciberespaço tem crescimento exponencial, bem como sua utilização por meio dos dispositivos móveis, aumentando a produção, o compartilhamento, a colaboração e a interação entre os sujeitos.

Entretanto, muitas vezes os sujeitos informacionais acabam tendo dificuldades para encontrar as informações que necessitam. Existem mecanismos de busca que oferecem ferramentas e funcionalidades para a

Inf. Inf., Londrina, v. 22, n. 2, p. 481 - 496, maio/ago., 2017. http:www.uel.br/revistas/informacao/ 
Encontrabilidade da Informação desejada, mas nem sempre são eficientes e proporcionam satisfação dos sujeitos.

A partir disso, a Arquitetura da Informação possui princípios que auxiliam no projeto e no desenvolvimento de ambientes informacionais digitais com uma abordagem centrada no usuário, otimizando o acesso e o uso da informação.

Assim, a Arquitetura da Informação a partir Rosenfeld, Morville e Arango (2015) que a definem como o desenho estrutural em ambientes informacionais compartilhados, a fim de facilitar a realização de tarefas e o acesso intuitivo aos conteúdos pelos usuários, favorecendo a usabilidade e a encontrabilidade. Também é uma arte e ciência para a estrutura e classificação dentro de websites e intranets a fim de ajudar os indivíduos a encontrarem seu caminho para o conhecimento.

A partir destas entre outras definições atribuídas pelos autores acima, verifica-se que uma arquitetura da informação deve contemplar elementos de acordo com os sujeitos informacionais, a fim que favoreça a eficiência da encontrabilidade de informações.

Morville (2005) descreve que Findability, traduzido para português "Encontrabilidade", refere-se à qualidade de localização e/ ou navegação; grau de facilidade de encontrar e/ou localizar um determinado objeto; grau em que um sistema ou ambiente suporta a navegação e a recuperação. Refletindo sobre essas definições, a Encontrabilidade permeia todo o ambiente, assim o nível ou grau que esteja interfere diretamente na eficiência da localização, navegação e recuperação de informações.

No contexto da Ciência da Informação, Vechiato e Vidotti (2014) sugeriram uma perspectiva teórica do termo Encontrabilidade da Informação que ocorre na interseção entre $o$ ambiente informacional e os sujeitos informacionais. Compreende-se que a Encontrabilidade da Informação está associada à Arquitetura da Informação e à Mediação Infocomunicacional, oferecendo subsídios nos processos de organização, representação, recuperação e disseminação da informação nos ambientes informacionais digitais. Considera também a Intencionalidade do sujeito como elemento 
fundamental que conduz a atender as necessidades dos sujeitos informacionais.

Neste sentido, os autores desenvolveram atributos e recomendações que favorecem a Encontrabilidade da Informação no ambiente informacional, preocupando-se, inclusive, com a apropriação da informação pelos sujeitos. Esses atributos são descritos na subseção a seguir.

\subsection{Atributos da Encontrabilidade da Informação}

Correspondem aos ambientes informacionais que podem ser analógicos, digitais e híbridos e contemplando uma arquitetura da informação top-down ou bottom-up que compreenda os processos informacionais e fluxos infocomunicacionais envolvidos. (VECHIATO; VIDOTTI, 2014). O Quadro 1 apresenta os atributos:

Quadro 1 - Atributos da Encontrabilidade da Informação (AEI)

\begin{tabular}{|c|l|}
\hline ATRIBUTOS & \multicolumn{1}{|c|}{ DESCRIÇÃO } \\
\hline $\begin{array}{c}\text { Taxonomias } \\
\text { Navegacionais }\end{array}$ & $\begin{array}{l}\text { As taxonomias navegacionais relacionam-se com a } \\
\text { organização da informação. Vechiato (2013) define } \\
\text { como uma estruturação do conteúdo informacional } \\
\text { a fim de auxiliar a recuperação da informação por } \\
\text { meio de mecanismo de busca e apresentação da } \\
\text { informação em categorias no momento de } \\
\text { navegação definidos pela organização e títulos dos } \\
\text { conteúdos. }\end{array}$ \\
\hline $\begin{array}{c}\text { Instrumentos de } \\
\text { controle } \\
\text { terminológico }\end{array}$ & $\begin{array}{l}\text { Relaciona-se com os vocabulários controlados que } \\
\text { subsidiam a representação das informações. }\end{array}$ \\
\hline $\begin{array}{c}\text { Folksonomias } \\
\text { Metadados }\end{array}$ & $\begin{array}{l}\text { Proporciona que o sujeito atribua termos aos } \\
\text { conteúdos informacionais permitindo uma } \\
\text { classificação social. }\end{array}$ \\
\hline $\begin{array}{c}\text { Mediab̧ãizo dos descrição dos recursos informacionais, } \\
\text { assim facilitando a recuperação da informação. }\end{array}$ \\
\hline informáticos & $\begin{array}{l}\text { Relaciona-se no gerenciamento e recuperação da } \\
\text { informação no que tange o desenvolvimento de } \\
\text { sistemas, dispositivos, banco de dados e interfaces. }\end{array}$ \\
\hline Affordances & Oferece pistas que são significativas aos sujeitos. \\
\hline Wayfinding & Orientação espacial que facilita a localização de \\
\hline
\end{tabular}

Inf. Inf., Londrina, v. 22, n. 2, p. 481 - 496, maio/ago., 2017. 


\begin{tabular}{|c|l|}
\hline $\begin{array}{c}\text { Descobertas de } \\
\text { informações }\end{array}$ & $\begin{array}{l}\text { informações na interface. } \\
\text { e os mecanismos de busca que favorecem a } \\
\text { descoberta de novas informações. }\end{array}$ \\
\hline $\begin{array}{c}\text { Acessibilidade e } \\
\text { Usabilidade }\end{array}$ & $\begin{array}{l}\text { A usabilidade diz respeito ao sistema oferecer } \\
\text { qualidade de interação entre os usuários e esses } \\
\text { ambientes no contexto de uso (interface), enquanto } \\
\text { que a acessibilidade significa facilidade de acesso } \\
\text { para todos os sujeitos. }\end{array}$ \\
\hline $\begin{array}{c}\text { Mediação dos } \\
\text { sujeitos institucionais }\end{array}$ & $\begin{array}{l}\text { Refere-se aos sujeitos institucionais envolvidos } \\
\text { com os processos informacionais. }\end{array}$ \\
\hline $\begin{array}{c}\text { Mediação dos } \\
\text { sujeitos } \\
\text { informacionais }\end{array}$ & $\begin{array}{l}\text { Os sujeitos realizam ações infocomunicacionais na } \\
\text { produção e organização da informação no } \\
\text { ambiente de acordo com suas experiências, } \\
\text { comportamento. Relacionando diretamente com a a } \\
\text { Intencionalidade. }\end{array}$ \\
\hline $\begin{array}{c}\text { Mobilidade, } \\
\text { Intencionalidade } \\
\text { ubiquidade }\end{array}$ & $\begin{array}{l}\text { Enfatiza as experiências e habilidades dos sujeitos } \\
\text { informacionais. }\end{array}$ \\
\hline $\begin{array}{l}\text { Relaciona-se com o meio ambiente tanto com } \\
\text { aspectos externos como internos que influenciam } \\
\text { na dinâmica dos sujeitos informacionais } \\
\text { conseguirem encontrar as informações que } \\
\text { necessitam por meio de diversos dispositivos. }\end{array}$ \\
\hline
\end{tabular}

Fonte: Adaptado VECHIATO; VIDOTTI (2014)

Os atributos de Encontrabilidade da informação orientam projetos de Arquitetura da Informação para que possam estar de acordo com as necessidades informacionais dos sujeitos.

Para melhor conhecer o usuário, podem ser aplicadas ferramentas para auxiliar no mapeamento e na coleta de dados visando identificar seu comportamento, além de realizar estudos com usuários visando avaliar sua interação com o ambiente.

Inf. Inf., Londrina, v. 22, n. 2, p. 481 - 496, maio/ago., 2017. http:www.uel.br/revistas/informacao/ 


\section{$3 \quad$ AMBIENTE INFORMACIONAL DIGITAL TED}

A organização Technology, Entertainment and Design surgiu em 1984, com formato de conferência, idealizada por Richard Saul Wurman. Os temas abordados na primeira conferência foram sobre tecnologia, entretenimento e design, que dão origem a sigla TED. O motivo da escolha foi que as três áreas são convergentes e tem foco em criatividade. (WURMAN,2005, grifo nosso)

Entre 2001-2006, além da conferência anual, surgiram mais três tipos de eventos: TED Global- realizada em vários locais ao redor do mundo; TED Prize - um concurso que tem o objetivo de premiar o melhor projeto com apoio financeiro, para concretizar o seu projeto; TED Talks - uma série de podcasts de áudio e vídeo de conteúdo disponibilizado gratuitamente online (TED, 2017, tradução nossa). Esses foram os primeiros programas lançados que abriram o caminho para desenvolvimento da organização.

Em 2007, com o crescimento do uso da Web para disseminar conteúdos, a organização $T E D$, desenvolveu o ambiente para publicação dos vídeos das palestras de forma gratuita. O conteúdo dos vídeos são assuntos diversificados advindos de várias áreas do conhecimento, assim configura-se como uma palestra com discurso curto com duração de no máximo dezoito minutos. (TED, 2017, tradução nossa)

A missão organizacional ficou evidente nas informações sobre a organização no próprio ambiente. A missão é divulgar as ideias e, para isso, eles selecionam pessoas de todas as disciplinas e cultura para uma compreensão mais profunda do mundo (TED, 2017, tradução nossa)

Dessa forma, a interação no evento ocorre de forma que proporciona tanto ao público presencial ou online uma nova perspectiva sobre algum assunto ou motivando em sua vida profissional, acadêmica, pessoal, social, de maneira que o palestrante e o público possam interagir com recursos de multimídia.

Os palestrantes são de várias nacionalidades, logo falam línguas diferentes, para que isso não seja uma barreira ao usuário que assiste. É

Inf. Inf., Londrina, v. 22, n. 2, p. 481 - 496, maio/ago., 2017. http:www.uel.br/revistas/informacao/ 
oferecida a tradução dos vídeos por legendas possibilitando a compreensão do conteúdo do discurso, bem como esses palestrantes procuram difundir suas ideias, principalmente, com sujeitos outras áreas de conhecimento e focando em questões de interesse público (ANDERSON, 2016)

Desse modo, entende-se que o vídeo é um tipo de informação composta de elementos como imagem e sons a partir da afirmação de Semeler e Rozados (2012) consideram o vídeo digital como um suporte informacional para comunicação audiovisual que compõe uma memória dialógica, possibilitando a recuperação, armazenamento e a disseminação pelas tecnologias digitais.

De modo geral, a proposta do ambiente TED é a disseminação das ideias, juntamente com os programas e iniciativas, bem como os canais de comunicação que favorecem ao acesso à informação e ao conhecimento das palestras. Dessa forma, buscando atingir o objetivo organizacional: qual a melhor forma de divulgar essas ideias (TED, 2017, tradução nossa). Partindo deste objetivo da organização e contextualização do histórico da mesma, destacamos que a pesquisa teve enfoque no ambiente informacional digital da TED.

O ambiente TED.com é atualizado regularmente com novos recursos solicitados por usuários, por exemplo, um leitor de vídeo avançado, páginas compatíveis com dispositivos móveis. Também os usuários que realizam o cadastro têm recursos disponíveis como marcar vídeos como favorito, comentar e colaborar na tradução dos vídeos (PELTIER-DAVIS, 2015).

Neste ambiente tem o TED Talks, que são os vídeos, apresentam uma descrição do tema da palestra e sobre o palestrante que levam a outra página com mais informações sobre o autor e reportagens da própria organização sobre o mesmo.

Para Carlo (2014) o TED Talks, que são os vídeos, configura-se como uma ferramenta de popularização para conteúdos científicos, uma comunicação científica online por meio de vídeos para divulgar os resultados. Assim, os conteúdos científicos são contextualizados em uma palestra

Inf. Inf., Londrina, v. 22, n. 2, p. 481 - 496, maio/ago., 2017. http:www.uel.br/revistas/informacao/ 
dinâmica e inspiradora de modo que é diferente de um evento científico padrão que demonstram todos os procedimentos metodológicos de uma pesquisa.

Além deste programa, tem o ambiente TED-Ed que permite ao usuário criar lições por meio de vídeos e contam com recursos interativos que auxiliam na aprendizagem. Encontra-se em outra plataforma web própria, segundo Peltier-Davis (2015, p.3 e 4) que aponta como uma ferramenta relevante aos profissionais da informação e educadores, de forma que promove uma rede de compartilhamento para criar e compartilhar lições construídas em vídeo.

\section{RESULTADOS: APRESENTAÇÃO E DISCUSSÃO}

As organizações sejam com fins ou sem fins lucrativos constroem ambientes informacionais digitais na web como uma forma de disseminar seus produtos e serviços. Rosenfeld, Morville e Arango (2015) consideram que os ambientes informacionais digitais são meios de unificação de acesso aos formatos digitais dentro de muitas organizações.

A missão da organização do TED corresponde a afirmação de Campello (2000) que entende que a razão de existir de uma organização possa ser a divulgação de informações. Logo, para que as informações sejam divulgadas, o próprio ambiente tem que estar estruturado e objetivo aos sujeitos.

Dessa forma, um ambiente informacional digital deve ser acessível e ser fácil de ser encontrado possibilitando o uso, bem como o planejamento deve estar voltado às necessidades informacionais do usuário de modo a favorecer o acesso e uso da informação. Para Rosenfeld, Morville e Arango (2015), a Arquitetura da Informação do ambiente deve estar em consonância com a interseção de três dimensões: o contexto (organizacional), o conteúdo (informacional) e o usuário.

Sendo assim, a partir da observação do ambiente TED, percebeu-se os elementos conteúdo, contexto e usuário apresentados na Figura 1 que segue:

Inf. Inf., Londrina, v. 22, n. 2, p. 481 - 496, maio/ago., 2017. http:www.uel.br/revistas/informacao/ 
Figura 1 - Contexto, conteúdo e usuário no ambiente TED

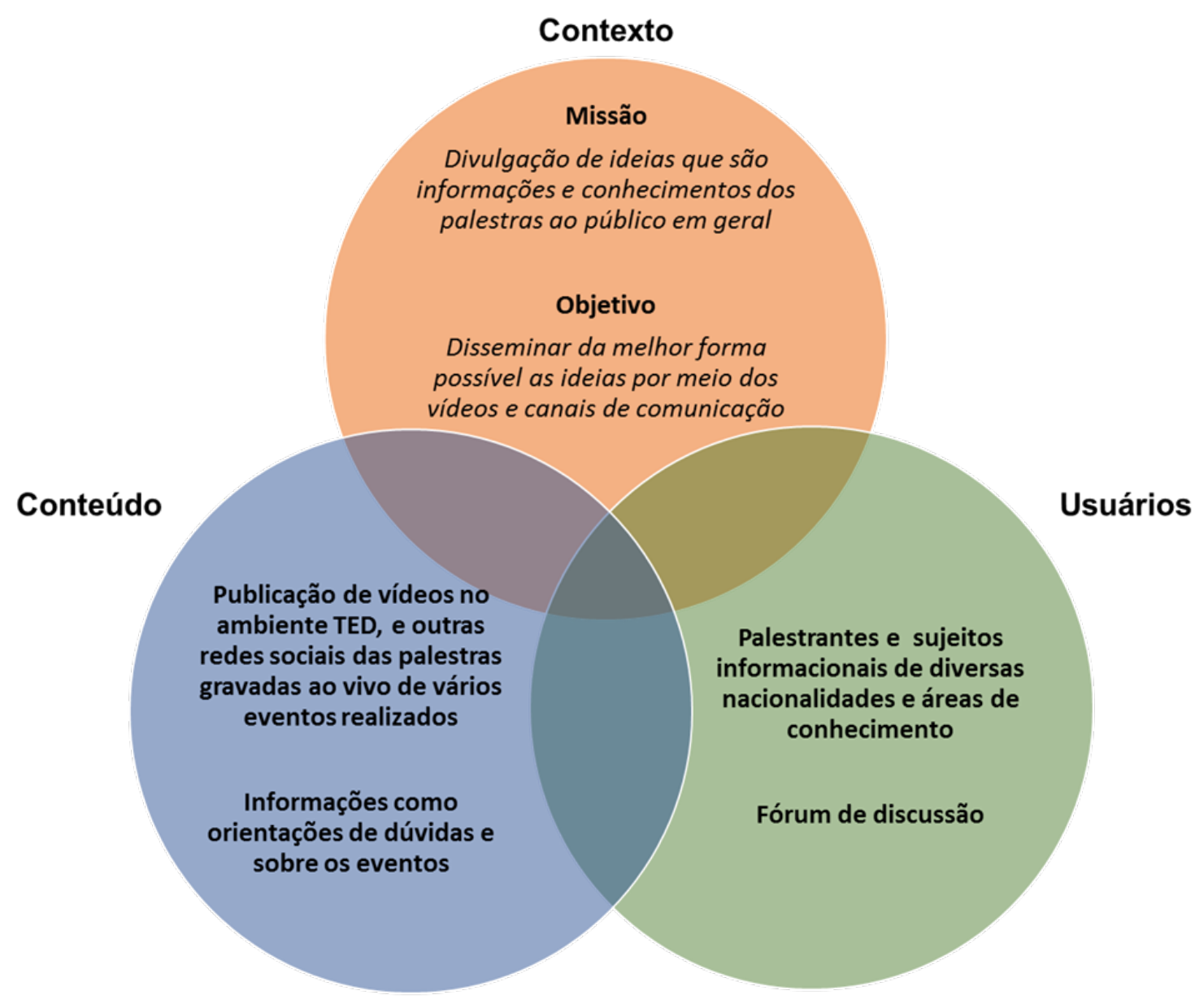

Fonte: Adaptada de Rosenfeld, Morville e Arango (2015)

Conforme observado na figura, o Contexto do ambiente TED dialoga com a missão organizacional no que tange divulgação de ideias, por sua vez, essas ideias são referentes ao conjunto de informações e conhecimentos disseminados ao sujeitos informacionais, assim o objetivo é estabelecer as melhores formas de divulgar as ideias por canais de comunicação que possibilitam o acesso aos vídeos. Dessa forma, percebe-se que o Usuário tem diversos perfis caracterizando-se como usuários heterogêneos, pois os sujeitos que o utilizam são de diferentes nacionalidades e culturas, mas o ambiente TED disponibiliza um espaço para discussão e comentários sobre os assuntos abordados nos vídeos entre os sujeitos informacionais. O Conteúdo envolve

Inf. Inf., Londrina, v. 22, n. 2, p. 481 - 496, maio/ago., 2017. http:www.uel.br/revistas/informacao/ 
os vídeos digitais que tem como conteúdos assuntos diversos advindos de diferentes áreas do conhecimento, além disso, um espaço dedicado às informações como orientações de dúvidas e sobre os eventos. Em relação à publicação de vídeos ocorre tanto no próprio ambiente ou em outras plataformas de vídeos que potencializam a comunicação e disseminação de informações e conhecimentos.

Os três elementos - contexto, conteúdo e usuário - possibilitaram uma análise do ambiente a partir dos atributos de Encontrabilidade da informação observando quais atributos estão presentes no ambiente TED. No Quadro 2, apresenta os atributos e as opções de $\operatorname{SIM}(\mathrm{S})$ e NÃO (N) que são referentes se o ambiente contempla ou não o atributo, seguido de observações que descrevem como tais atributos está disposto no ambiente TED.

Quadro 2 - Análise dos atributos no ambiente TED

\begin{tabular}{|c|c|c|l|}
\hline ATRIBUTOS & $\begin{array}{c}\text { SIM } \\
\text { (S) }\end{array}$ & $\begin{array}{c}\text { NÃO } \\
\text { (N) }\end{array}$ & \multicolumn{1}{|c|}{ OBSERVAÇÕES } \\
\hline $\begin{array}{c}\text { Taxonomias } \\
\text { navegacionais }\end{array}$ & $\mathbf{X}$ & & $\begin{array}{l}\text { As taxonomias navegacionais estão presentes } \\
\text { no menu do ambiente. }\end{array}$ \\
\hline $\begin{array}{c}\text { Instrumentos de } \\
\text { controle terminológico }\end{array}$ & $\mathbf{X}$ & $\begin{array}{l}\text { Embora apresente tags que são atribuídas aos } \\
\text { vídeos, não percebeu algum controle } \\
\text { terminológico apontado pelo ambiente. }\end{array}$ \\
\hline Folksonomias & $\mathbf{X}$ & $\begin{array}{l}\text { Embora possibilite que os sujeitos possam } \\
\text { classificar os conteúdos por meio de adjetivos } \\
\text { que qualificam os vídeos por exemplo, } \\
\text { informativo, persuasivo etc.), não possibilita } \\
\text { que atribuam termos ou que postem vídeos. }\end{array}$ \\
\hline Metadados & $\mathbf{X}$ & $\begin{array}{l}\text { São usados para descrição de seus conteúdos, } \\
\text { como título, descrição da palestra tempo de } \\
\text { duração do vídeo e palavras-chave, } \\
\text { informações sobre o palestrante e tags. }\end{array}$ \\
\hline $\begin{array}{c}\text { Mediação dos } \\
\text { informáticos }\end{array}$ & $\mathbf{X}$ & $\begin{array}{l}\text { O ambiente TED tem um aplicativo para } \\
\text { smartphones que facilita aos sujeitos de baixar } \\
\text { os vídeos ou apenas escutar como podscast, } \\
\text { além disso tem o ambiente TED-Ed que } \\
\text { oferece uma plataforma para elaboração de } \\
\text { aulas audiovisuais. }\end{array}$ \\
\hline Affordances & $\begin{array}{l}\text { O mapa do site oferece recursos hipertextuais } \\
\text { que mudam de cor (de cinza para preto) } \\
\text { quando o cursor do mouse for passado acima }\end{array}$ \\
\hline
\end{tabular}

Inf. Inf., Londrina, v. 22, n. 2, p. 481 - 496, maio/ago., 2017. http:www.uel.br/revistas/informacao/ 


\begin{tabular}{|c|c|c|c|}
\hline & & & $\begin{array}{l}\text { do hipertexto. Assim descobrindo informações } \\
\text { sobre outros programas e iniciativas, mais } \\
\text { informações sobre os eventos. }\end{array}$ \\
\hline Wayfinding & $\mathbf{x}$ & & $\begin{array}{l}\text { Quando o sujeito informacional assiste um } \\
\text { vídeo, aparece no lado direito da tela } \\
\text { destacado com fonte em negrito "Watch next", } \\
\text { em português, "assistir ao próximo" que } \\
\text { recomenda os vídeos que tem assuntos } \\
\text { similares em relação ao vídeo atual. }\end{array}$ \\
\hline $\begin{array}{l}\text { Descobertas de } \\
\text { informações }\end{array}$ & $\mathbf{x}$ & & $\begin{array}{l}\text { São apresentados vídeos que se relacionam } \\
\text { com outros a partir de assuntos similares, } \\
\text { assim reúnem um conjunto em categorias que } \\
\text { auxiliam na descoberta de novas informações } \\
\text { no momento de naveqação e busca. }\end{array}$ \\
\hline $\begin{array}{c}\text { Acessibilidade e } \\
\text { usabilidade }\end{array}$ & $\mathbf{x}$ & & $\begin{array}{l}\text { Percebe alguns elementos de acessibilidade } \\
\text { como legendas de tradução, e como um } \\
\text { aspecto de usabilidade o sujeito tem } \\
\text { autonomia em fazer suas próprias playlists de } \\
\text { vídeos. }\end{array}$ \\
\hline $\begin{array}{l}\text { Mediação dos sujeitos } \\
\text { institucionais }\end{array}$ & $\mathbf{x}$ & & $\begin{array}{l}\text { O ambiente apresenta características de } \\
\text { gerenciamento dos recursos informacionais, } \\
\text { mas não aponta uma equipe específica. }\end{array}$ \\
\hline $\begin{array}{l}\text { Mediação dos sujeitos } \\
\text { informacionais }\end{array}$ & & $\mathbf{x}$ & $\begin{array}{l}\text { Os sujeitos informacionais não podem produzir } \\
\text { e organizar as informações, já que o ambiente } \\
\text { é gerenciado pelos sujeitos institucionais da } \\
\text { organização. }\end{array}$ \\
\hline Intencionalidade & $\mathbf{x}$ & & $\begin{array}{l}\text { A preocupação com a intencionalidade dos } \\
\text { sujeitos apresenta-se em possibilitar que os } \\
\text { sujeitos possam classificar os vídeos de acordo } \\
\text { com adjetivos, mencionados no atributo } \\
\text { "Folksonomias". }\end{array}$ \\
\hline $\begin{array}{l}\text { Mobilidade, } \\
\text { convergência, } \\
\text { ubiquidade }\end{array}$ & $x$ & & $\begin{array}{l}\text { Neste atributo o ambiente TED corresponde a } \\
\text { sua missão que é a divulgação de ideias por } \\
\text { meio do aplicativo para smartphones e as } \\
\text { conferências para diferentes públicos } \\
\text { possibilitando onipresença em diversos } \\
\text { contextos, assim proporcionando } \\
\text { pervasividade pelos seus canais de } \\
\text { comunicação e informação. }\end{array}$ \\
\hline
\end{tabular}

Fonte: Elaborado pelos autores

Os atributos tais como os instrumentos de controle terminológico, Folksonomias e mediação dos sujeitos informacionais tem potencial de beneficiar os sujeitos no ambiente. Os conteúdos informacionais são produzidos e organizados pela organização TED, porém podem ser disponibilizados recursos que permitissem uma maior participação dos sujeitos

Inf. Inf., Londrina, v. 22, n. 2, p. 481 - 496, maio/ago., 2017. http:www.uel.br/revistas/informacao/ 
informacionais, como a possibilidade de atribuir tags, potencializando a representação da informação e, consequentemente, favorecendo um maior grau de Encontrabilidade da Informação disponibilizada.

Além desses atributos, a ausência de alguns elementos pode interferir na apropriação da informação pelos sujeitos, por exemplo, o ambiente TED oferece legendas de tradução, mas falta o recurso que traduza o ambiente para outros idiomas, assim considerando como uma barreira para encontrar os vídeos, que contém informações relevantes aos sujeitos.

\section{CONSIDERAÇÕES FINAIS}

$\mathrm{Na}$ avaliação do ambiente informacional digital $T E D$, o contexto se insere na disseminação de informação por meio de recursos audiovisuais divulgados por canais de comunicação como redes sociais, plataforma de vídeo, aplicativo móvel, eventos em diferentes lugares para diferentes públicos, percebendo que a informação se torna pervasiva por percorrer diferentes ambientes da organização.

Identificamos as dimensões contexto, conteúdo e usuário a partir da ótica da Arquitetura da Informação, sendo as características organizacionais, a missão, objetivos, as formas de divulgação e compartilhamento de informação e conhecimento, assim compreendendo que os atributos Encontrabilidade da Informação apontam que alguns dos processos informacionais realizados pelos sujeitos institucionais são organização e representação da informação, mas esses processos informacionais podem ter mais participação dos sujeitos informacionais.

Para tanto, a ausência de alguns atributos demonstra que o ambiente TED pode potencializar as divulgações de ideias considerando os sujeitos informacionais no processo de produção e organização tornando o ambiente mais colaborativo e interativo.

Vale ressaltar que para a satisfação do sujeito informacional devem ser consideradas suas experiências e habilidades, ou seja, a Intencionalidade que

Inf. Inf., Londrina, v. 22, n. 2, p. 481 - 496, maio/ago., 2017. http:www.uel.br/revistas/informacao/ 
ocorre pelas ações infocomunicacionais que oferecem o dinamismo nos processos informacionais que estimulam na formulação de funcionalidades de acordo com as necessidades informacionais dos sujeitos informacionais e institucionais.

Portanto, os atributos da Encontrabilidade da Informação permitiram perceber o impacto da missão organizacional no ambiente TED no que tange às formas definidas para o compartilhamento e a disseminação do conhecimento por meio dos vídeos divulgados em redes sociais, dispositivo móvel e principalmente no ambiente informacional digital que são essenciais para garantir acesso à informação e a satisfação dos sujeitos informacionais para realização efetiva de sua missão organizacional.

\section{REFERÊNCIAS}

ANDERSON, C. TED Talks: o guia oficial do TED para falar em público. Rio de Janeiro: Intrínseca, 2016. 240 p.

CAMPELLO, B. S. Organizações como fonte de informação. In: CENDÓN, B. V; KREMER, J. M. (Org.). Fontes de informação para pesquisadores e profissionais. Belo Horizonte: UFMG, 2000. Cap. 2. p. 3548.

CARLO, G. S. New trends in knowledge dissemination: TED Talks. Acta Sci. Lang. Cult., Maringá, v. 36, n. 2, p.121130. 2014. Disponível em: $<$ http://dx.doi.org/10.4025/actascilangcult.v36i2.22619>. Acesso em: 22 abr. 2017.

MORVILLE, P. Ambient findability. Sebastopol: O’Really, 2005.

PELTIER-TEDDAVIS, C. A. TED (Technology, Entertainment and Design): Global Conference/ldea Sharing Platform. In: The Cybrarian's Web 2: An A-Z Guide to Free Social Media Tools, Apps, and Other Resources. [s.i]: Information Today, 2015. p. 17.

ROSENFELD, L; MORVILLE, P; ARANGO, J. Information Architecture: for the Web and Beyond. Sebastopol: O'Reilly Media, 2015. 454 p.

Inf. Inf., Londrina, v. 22, n. 2, p. 481 - 496, maio/ago., 2017. http:www.uel.br/revistas/informacao/ 
SEMELER, A. R.; ROZADOS, H. B. F. Imagem, Informação e Tecnologia: vídeo digital como objeto de estudo para Ciência da Informação. Informação \& Informação, Londrina, v. 17, n. 1, p. 78-92, jul. 2012. Disponível em: <http://dx.doi.org/10.5433/1981-8920.2012v17n1p78>. Acesso em: 23 mai. 2017.

TED. History of TED. Disponível em: <https://www.ted.com/about/ourorganization/history-of-ted>. Acesso em: 09 jun. 2017.

VECHIATO, F. L. Encontrabilidade da informação: contributo para uma conceituação no campo da Ciência da Informação. 2013. 206 f. Tese (Doutorado em Ciência da Informação) - Faculdade de Filosofia e Ciências de Marília. Universidade Estadual Paulista, 2013. Disponível em: <http://hdl.handle.net/11449/103365t>. Acesso em: 15 mai. 2016.

VECHIATO, F. L.; VIDOTTI, S. A. B. G. Encontrabilidade da informação. São Paulo: Cultura Acadêmica, 2014. 204 p. (Coleção PROPG Digital-UNESP). Disponível em: <http://hdl.handle.net/11449/126218>. Acesso em: 21 mai. 2017.

WURMAN, R. S. Ansiedade da informação 2. São Paulo: Cultura, 2005. 299 p.

\section{Title}

Findability of information in the environment Technology, Entertainment and Design

Introduction: The dissemination and sharing of information and knowledge are the main objective of digital information environments, such as Technology, Entertainment and. Design (TED), whose purpose is to promote the lectures that are recorded, which deal with various subjects in digital video format. Considering the relevance of this environment, it is important to reflect on the available Findability of Information, to understand if its projecTED Information Architecture includes attributes that facilitate the location, access, use and appropriation of information by its users. Objective: Thus, the objectives of this research were to evaluate the Findability of Information in the digital information environment TED based on the attributes of the study and to analyze the results considering the dimensions of the Information Architecture, which are content, context and user. Methodology: This is a documentary and exploratory research, with a qualitative approach and using participant observation. Results: The results reveal that the Findability of Information attributes present in the TED indicate consonance with the organizational mission and provide the interaction of the users of information with the interface. Conclusions: The absence of some attributes may compromise the appropriation of information by users of information.

Keywords: Findability of Information. Information Architecture. Digital information environment. Dissemination of information.

Inf. Inf., Londrina, v. 22, n. 2, p. 481 - 496, maio/ago., 2017. 


\section{Titulo}

Encontrabilidad de la información en el ambiente Technology, Entertainment and Design

\section{Resumen:}

Introducción: La diseminación y la compartición de la información y conocimiento son el principal objetivo de los ambientes de información digitales, como la organización Technology, Entertainment and Design (TED), que tiene el propósito de divulgar las conferencias que son grabadas, las cuales abordan diversos asuntos en formato de vídeo digital. Considerando la relevancia de este ambiente, se torna importante reflexionar al respecto de la Encontrabilidad de la Información disponible, con vistas a comprender si la Arquitectura de la Información planeada contempla los atributos que facilitan la localización, el acceso, el uso y la apropiación de la información por sus usuarios. Objetivo: De este modo, los objetivos de esta investigación fueron evaluar la Encontrabilidad de la Información en el ambiente informacional digital TED a partir de los atributos del referido estudio y analizar los resultados a la luz de las dimensiones de la Arquitectura de la Información, siendo ellas contenido, contexto y usuario. Metodología: Se trata de una investigación documental y exploratoria, con abordaje cualitativo y observación participante. Resultados: Los resultados revelan que los atributos de Encontrabilidad de la información presentes en TED demuestran consonancia con la misión organizacional y promueven la interacción del sujeto informacional con la interfaz. Conclusiones: A falta de algunos atributos puede comprometer la apropiación de la información para los sujetos informacionales.

Palabras clave: Encontrabilidad de la Información. Arquitectura de la Información. Ambiente informacional digital. Diseminación de la información

Recebido: 30.08 .2017

Aceito: 30.09 .2017

Inf. Inf., Londrina, v. 22, n. 2, p. 481 - 496, maio/ago., 2017. 